\title{
Explorando potencialidades do Pensamento Computacional de forma (des)plugada com estudantes da rede estadual de educação de Mato Grosso
}

\author{
Sabrina Bourscheid Sassi \\ Instituto de Educação \\ UFMT/Universidade Federal de \\ Mato Grosso \\ Cuiabá/ Mato Grosso/ Brasil \\ sabrinabsassi@gmail.com
}

\author{
Cristiano Maciel \\ Instituto de Educação \\ UFMT/Universidade Federal de \\ Mato Grosso \\ Cuiabá/ Mato Grosso/ Brasil \\ crismac@gmail.com
}

\author{
Vinícius Carvalho Pereira \\ Instituto de Linguagens \\ UFMT/ Universidade Federal de \\ Mato Grosso \\ Cuiabá/ Mato Grosso/ Brasil \\ viniciuscarpe@gmail.com
}

A Base Nacional Curricular Comum (BNCC), enquanto instrumento de gestão pedagógica das escolas públicas e privadas do Brasil, faz referências precisas ao Pensamento Computacional (PC), além de diversos aspectos correlatos, como Cultura Digital, Tecnologias Digitais de Informação e Comunicação (TDIC), Redes Sociais, Algoritmos etc. [1]. Embora a definição de PC não seja apresentada na BNCC, o tema é explicitamente referenciado neste documento, principalmente na Área de Matemática quando o texto se refere aos processos matemáticos, nas unidades temáticas Álgebra, Números, Geometria e Probabilidade e Estatística. O mesmo se dá quando o documento, de modo mais geral, afirma que “(...) a área de Matemática, no Ensino Fundamental, centra-se na compreensão de conceitos e procedimentos em seus diferentes campos e no desenvolvimento do pensamento computacional, visando à resolução e formulação de problemas em contextos diversos" [[1], p.471].

Wing [2] define o PC como processos de pensamento envolvidos na formulação de um problema e que expressam sua solução ou soluções de forma eficaz, de modo que uma máquina ou uma pessoa possa realizar. Portanto, o PC é tido como um conjunto de habilidades e atitudes que são exigidas para o século XXI e estão relacionadas à resolução de problemas, podendo ser aplicadas transversalmente ao conteúdo de disciplinas, tanto na educação básica, quanto na educação superior.

Ao analisar o cenário das escolas públicas brasileiras quanto ao acesso e à disponibilidade de tecnologias, bem como o desempenho dos alunos indicado nas avaliações externas e internas de uma maneira geral, identificamos lacunas que podem auxiliar as práticas pedagógicas de professores e ajudar os alunos imersos na cultura digital. Este trabalho busca uma reflexão em torno do seguinte questionamento: Como os alunos, professor e coordenação pedagógica percebem o uso da Computação Desplugada para o ensino de Pensamento Computacional e das habilidades Matemáticas? Deste modo, o objetivo desta pesquisa é analisar o uso da Computação Desplugada como abordagem para o desenvolvimento do Pensamento Computacional e de habilidades

Fica permitido ao(s) autor(es) ou a terceiros a reprodução ou distribuição, em parte ou no todo, do material extraído dessa obra, de forma verbatim, adaptada ou remixada, bem como a criação ou produção a partir do conteúdo dessa obra, para fins não comerciais, desde que sejam atribuídos os devidos créditos à criação original, sob os termos da licença CC BY-NC 4.0.

EduComp'21, Abril 26-30, 2021, Jatai, Goiás, Brasil (On-line)

(C)2021 Copyright mantido pelo(s) autor(es). Direitos de publicação licenciados à Sociedade Brasileira de Computação (SBC).
Matemáticas no processo de ensino-aprendizagem na disciplina de Matemática no Ensino Fundamental.

Dada a característica do objeto de estudo, como estratégia metodológica utilizaremos a pesquisa-ação [3][4], suportada pela investigação-ação, que caracteriza a prática realizada no contexto da pesquisa no âmbito escolar, visando a uma melhoria dos processos de ensino-aprendizagem, focando nos problemas existentes na escola selecionada e vivenciados pelos professores. Buscamos, assim, possíveis soluções com a participação de alunos, professor, coordenação pedagógica e a pesquisadora, com adoção da abordagem qualitativa [5]. Para tal, a pesquisa será desenvolvida com crianças de idade entre 12 (doze) e 15 (quinze) anos, alunos do $7^{\circ}$ ano, $8^{\circ}$ ano e $9^{\circ}$ ano matutinos, do Ensino Fundamental, de uma escola Estadual de Sorriso - MT. A participação dos alunos nesta pesquisa consistirá no desenvolvimento de atividades (des)plugadas com a mediação da professora/pesquisadora e da professora regente durante todas as etapas do processo que ocorrerá em uma hora/aula remota de Matemática na semana, do $2^{\circ}$ ao $4^{\circ}$ bimestre do ano letivo de 2021. Todas as ações serão devidamente autorizadas pelos sujeitos, responsáveis e instituições.

Para a coleta de dados serão utilizados questionário e grupo focal com os alunos participantes da pesquisa, entrevistas com a professora regente de matemática e com a coordenação pedagógica, bem como a observação participante durante todos os momentos da investigação-ação, com foco no professor, coordenação pedagógica e alunos participantes. Os dados coletados serão analisados e triangulados.

Acreditamos que esta pesquisa possa orientar o fazer pedagógico utilizando-se da computação desplugada e do projeto Computer Science Unplugged (CS Unplugged) dentro do currículo escolar, com base nos objetivos de aprendizagem da Matemática previstos na BNCC.

\section{PALAVRAS-CHAVE}

Pensamento Computacional, Computação Desplugada, Matemática, Ensino Fundamental

\section{AGRADECIMENTOS}

Essa pesquisa conta com o apoio do Conselho Nacional de Desenvolvimento Científico e Tecnológico - CNPq e da Secretaria de Estado de Educação de Mato Grosso-SEDUC. 


\section{REFERÊNCIAS}

[1] Brasil. MEC. (2018) Base Nacional Curricular Comum (BNCC). Disponível $\mathrm{em}:<\mathrm{http} / / /$ basenacionalcomum.mec.gov.br/images/BNCC_EI_EF_110518_ver saofinal_site.pdf $>$. Acesso em: 20/02/2021.

[2] J M. Wing. (2010). Computational Thinking: What and Why?. 17. out. 2010. Disponível

$<$ http://www.cs.cmu.edu/ CompThink/resources/TheLinkWing.pdf $>$. Acesso em: $31 / 10 / 2019$

[3] Denise Filippo. Estudo de Caso em Sistemas Colaborativos. 2011. In book: Sistemas Colaborativos, Edition: 1ed., Cap. 25, Publicado: Campus/Elsevier, Editora. Mariano Pimentel \& Hugo Fuks (Org.), pg..449-466

[4] Elliot, J. El cambio educativo desde la investigacion-accion. Ediciones Morata, S.L. 3 ed. Madrid. 1997.

[5] Denzin, N. K.; Lincoln, Y. S. O planejamento da pesquisa qualitativa: teorias e abordagens. 2. ed. Porto Alegre: Artmed, 2006 